\title{
Algumas observações sobre o Manifesto do Partido Comunista, o "eurocentrismo" e a questão colonial na Argélia
}

\author{
Some observations on the Communist Party Manifesto, Eurocentrism, and the colonial \\ question in Algeria
}

\section{Smail Hadj ALI*}

Como Samir Amin" afirma, "Nenhum texto escrito em meados do século XIX se mantém tão atual hoje em dia quanto o Manisfesto Comunista de 1848. Lidas atualmente, frases inteiras do texto correspondem à realidade contemporânea ainda melhor do que em 1848 . Partindo de premissas ainda latentes na época, Marx e Engels tiram conclusões que o desenrolar de 170 anos de história iria confirmar plenamente" (AMIN, 2018, p. 17).

Em relação a esta constatação, o autor aborda à luz de nossos tempos questões que reforçam e atestam a atualidade deste texto e, mais ainda, a atualidade do pensamento marxista.

Isto dado e considerando o limite do espaço que a redação me concedeu, nos interrogamos sobre uma única questão, dentre tantas outras levantadas por Samir Amin. E isto sem pretender esgotar todas as dimensões, dadas as razões aqui evocadas.

A questão se relaciona ao que o autor denomina “o eurocentrismo" abordado na parte relacionada à mundialização capitalista.

Neste sentido vamos nos ater às passagens que introduzem esta questão:

"Marx, mais do que ninguém, compreendera que o capitalismo tinha vocação para conquistar o mundo. Ele escreve numa época em que o capitalismo ainda estava longe de ter atingido sua complitude e retoma de suas origens esta vocação, a descoberta da America que inaugura a transição de três séculos mercantilistas para o capitalismo plenamente desenvolvido"3. O autor prossegue ressaltando: "Marx se alegra com esta mundialização, fenômeno novo na história da humanidade".

S. Amin, ilustra sua proposição citando a seguinte passagem do Manifesto : "A burguesia submeteu o campo à cidade ... e, desse modo preservou uma grande parte da população do endurecimento da vida no campo ... da mesma forma que ela subordinou as regiões rurais às cidades, as nações bárbaras e semi-civilizadas às nações civilizadas, ela subordinou os países agrícolas aos países industrializados, o Oriente ao Ocidente ... ".4

\footnotetext{
* Doutor em Ciências Sociais da Université de Haute Bretagne. Université d'Alger. E-mail: $<$ hadjazil@gmail.com >.

1 AMIN, Samir. O Manifesto comunista, 170 anos mais tarde. Argumentum, Vitória, v. 10, n. 2, p. 17-28, 2018.

2 Samir Amin, op.cit., p. 22.

3 Idem, p. 20.

4 Le Manifeste du Parti Communiste, p. 19, Éditions Sociales, 1959.
} 
Daí decorre que, como considera S. Amin, "Tudo está claro : Marx nunca foi um saudosista, que lamentasse o bons e velhos tempos. Ele sempre expressou pontos de vista modernistas, a ponto de parecer eurocêntrico ${ }^{5}$. Teria ido longe demais neste aspecto?"

S. Amin não responde diretamente sua própria questão. No entanto esboça uma resposta ao lembrar que no caso da China, quando lutava com as potências capitalistas préimperialistas, o Marx do Manifesto e forçosamente também Engels, dado que ambos escreveram o texto, "ainda pensavam" que a abertura comercial teve razão de ser. Afirmaram que "o preço baixo de seus produtos constitui a artilharia grossa que abre brechas ao longo da muralha chinesa e fazem capitular os bárbaros mais ferrenhamente hostis aos estrangeiros ". 6

Na realidade, S. Amin (2018, p. 22) indica que "não foi bem assim", "foram os canhões da marinha britânica que se sobrepuseram à concorrência dos produtos chineses. Sabemos que a se a Inglaterra chegou a dominar a Índia não foi porque sua indústria estivesse mais avançada. Ao contrário, foi o domínio sobre a Índia que permitiu que a Inglaterra assumisse a posição hegemônica no sistema capitalista do século XIX.” S. Amin (2018, p. 22) conclui e responde ao mesmo tempo à questão que colocava anteriormente da seguinte forma : "No entanto, $o$ Marx mais maduro soube deixar o eurocentrismo de sua juventude ${ }^{7}$. Marx sabia mudar de opinião à luz da evolução do mundo".

Sobre este ponto, é verdade que o Manifesto do Partido Comunista foi redigido por dois homens jovens, Engels com 28 anos e Marx com 30 anos. Neste caso a juventude deles é um argumento pertinente.

Considerando-se isto, Marx e Engels, já com mais idade, "teriam deixado" o eurocentrismo? Eurocentrismo este que por vezes caracterizaria tais percepções e posições sobre os países da periferia? Em especial aqueles denominados como "Oriente"?

Em suma, o eurocentrismo ressaltado por S. Amin, no caso da China, é apenas produto da juventude destes dois pensadores revolucionários e também fruto das ideias predominantes 8 sobre os povos e regiões da "periferia". Claro que este eurocentrismo não é tão forte na interpretação desses dois revolucionários. No entanto, eles não perceberam tal idealização apesar de toda a lucidez e atenção que tiveram.

Além das observações sobre a China, é justificável constatar que Marx, melhor que Engels, não pôde "deixar" totalmente uma visão de mundo eurocentrista, ou europeia, em relação à percepção que tinha sobre os países do “Oriente”. E isto de forma a evitar quaisquer afirmativas categóricas ou parcialidade na interpretação totalmente impossível nesta

\footnotetext{
5 Sublinado por nós.

6 Le Manifeste du Parti Communiste, p. 19, Éditions Sociales, 1959.

7 Sublinhado por nós.

8 “As ideias dominantes de uma época sempre foram apenas as ideias da classe dominante”. K. Marx, F. Engels, p. 33, op. cit.

"Em qualquer época as ideias são sempre as ideias dominantes; dito de outra forma, a classse que detém o poder material dominante da sociedade também detém o domínio espiritual”. K. Marx, F. Engels, L’idéologie allemande, p. 52, Éditions sociales, 1965.
} 
proposição, dado que adotamos como nossa a sua herança epistemológica, teórica e ideológica.

Observemos que esta visão está presente em seus trabalhos, independentemente da fase de submissão e domínio desses países pelas potências colonialistas. Certas posições e pontos de vista em seus escritos consagrados à Argélia mostram isto. Escritos que, à excessão das notas de Marx (1881) sobre o trabalho de Kowalewski ${ }^{9}$, são textos encomendados e frequentemente escritos por Engels, no período de 1848 a 1857. Marx, por sua vez, escreveu apenas um texto a respeito do general em chefe do exército francês, Bugeaud ${ }^{10}$.

Para além das ideias pré-concebidas e juízos de valores, esses textos se inserem no paradigma, enunciado no Manifesto. Paradigma este de "progresso" inevitável e de desenvolvimento da "civilização" também inevitável nas terras "bárbaras" da periferia, conquistadas pelas potências capitalistas europeias.

Questão: esse paradigma não se inscreveria, bem ou mal, em certa forma de positivismo determinista e de materialismo mecanicista? Formas estas presentes no pensamento socialista do século XIX e até mesmo do século XX.

No entanto, antes de avançarmos mais neste neste sentido, é necessário destacar que aquilo que entendemos por eurocentrismo, ou centrismo europeu, é uma visão esteriotipada, impregnada pela ideia de superioridade da civilização ocidental. Visão esta onde se percebe e se descreve rapidamente preconceitos e juízos de valor, os povos, as sociedades e as regiões não europeias.

No entanto, é importante ressaltar que o eurocentrismo que demonstram aqui e acolá não se reveste de agressividade, nem de apologia da violência ou de propostas racistas. E isto ao contrário do eurocentrismo de seus contemporâneos, a exemplo de Jules Ferry que, em 1882, exaltava a existência de raças inferiores em 1882 ou de Lord Cromer que proclamava a existência de "raças subordinadas".

Marx e Engels ressaltam, para condená-los e denunciá-los, os crimes, a violência e os excessos do exército francês. A conquista colonial é qualificada por Marx como "massacre", "uma guerra conduzida por soldados brutais", "tal como Bugeaud".

Marx recorda as crueldades, as atrocidades do exército colonial, através dos "Arábes queimados na gruta em que foram amontoados por um Marechal francês. "' Ele fazia alusão às queimas ordenadas pelos oficiais superiores franceses, tal como Pélissier, Cavaignac, dentre outros. Mais tarde, em suas notas sobre Kowalewski, ${ }^{12}$ que descrevia a apropriação e expropriação de terras agrícolas pelos colonizadores, ele escreve que a "rapinagem francesa salta aos olhos" e fala da "CHEGADA DOS CHACAIS FRANCESES"

\footnotetext{
9 A propriedade coletiva da terra : causas, histórico, e consequências de sua decomposição, 1879. O autor consagra uma parte de seu trabalho às formas de propriedade rural na Argélia La propriété collective du sol: causes, historique, et conséquences de sa décomposition, 1879.

10 Artigo redigido em novembro de 1857 e publicado em 1858, pela Enciclopédia americana.

${ }^{11}$ Marxisme et Algérie, Galissot et Badia, p. 90, Union Général D’Édition, 1976.

12 Idem, pp 206 et 208.

$13 \mathrm{Em}$ maiúscula no texto.
}

Argum., Vitória, v. 10, n. 2, p. 29-35, maio/ago. 2018. 
No entanto, a aversão, o mínimo que se pode dizer a esse respeito, que eles nutrem pelos colonizadores não os conduzem a rejeitar firmemente o empreendimento de destruição de uma sociedade, de um povo, de um país. Eles consideram que a conquista colonial levará necessariamente o desenvolvimento das forças produtivas ao seio da formação social colonizada. E isto de forma a provocar alterações positivas e significativas nas relações de produção e nas relações sociais.

Em seu primeiro texto sobre a Argélia, publicado pela Northern Star, em 22 de janeiro de 1848, precisamente um mês antes do manifesto Comunista, Galissot escreve ${ }^{14}$ : "Antes de tudo, a burguesia moderna, com a civilização, a indústria moderna, a ordem e as "luzes" que trazem consigo, são preferíveis ao senhor feudal ou à pilhagem em grande escala, e também ao estado bárbaro da sociedade a qual pertecem".

A recondução do chefe da resistência à conquista colonial, um sufi, chefe militar e homem de grande cultura, traído pelo rei de Marrocos, foi comentado da seguinte forma : "em termos gerais nossa opinião é de que ficou muito feliz com a prisão do chefe árabe. A luta dos Beduínos estava sem perspectiva, embora a forma como a guerra tenha sido conduzida por soldados brutais, tal qual Bugeaud, seja bem condenável, a conquista da Argélia foi um fato importante e propício para o progresso da civilização" ${ }^{15}$

Por outro lado, Engels considera que a conquista colocará um fim às "piratarias dos Estados bárbaros”, e que “a conquista da Argélia já forçara os beduínos de Túnis e de Trípoli, como também o Imperador do Marrocos, a se engajarem no caminho da civilização. Eles foram obrigados a encontrar outras ocupações no caminho da civilização que não a pirataria". A propósito desta rendição, se Engels lamenta "que a liberdade fosse destruída", afirma também que "não deveríamos esquecer que esses mesmos beduínos são um povo de ladrões, cujo principal meio de subsistência consistia em incursões nas casas um dos outros, ou nas casas dos cidadãos idosos tomando o que encontravam, massacrando todos aqueles que resistissem e vendendo o restante dos prisioneiros como escravos".

Essas passagens merecem algumas observações.

Engels parece ignorar que a pirataria, que foi uma "ocupação" dos "Estados bárbaros”, não existia mais em 1830. Além disso, durante a famosa batalha de Navarin em 1827, a frota otomana, reforçada por aquelas dos ditos "Estados bárbaros", foi totalmente destruída, quebrando definitivamente a áurea de potência marítima "bárbara".

\footnotetext{
14 Marxisme et Algérie, p. 27.

15 En 1834, Genty de Bussy, o intendente da Argélia conquistada, envia um relatório a seus superiores no qual declara : "Chamado a essa bela tarefa, de colonizar um reinado bárbaro, a França to mou para auxiliar sua atuação o mais possante meio civilizatório, a instrução. Ele envia um relatório a seus chefes no qual declara "Pacificar e esclarecer pouco a pouco os opositores, divulgar os beneficios da ciência que lhes faltou durante séculos, eis aí a nobre missão que a França proponhe e a cumprirá”. Cf., textos de Smaïl Hadj Ali : La mission civilisatrice, une insoutenable plaisanterie, et La mission civilisatrice, un processus de décivilisation, in El Watan, (Algérie) 05/06/2006 et 26/02/2007.
} 
A segunda observação diz respeito ao “caminho da civilização”. Esse “caminho” nunca será trilhado. Em contrapartida houve aquele caminho da colonização pela França, sob forma de protetorado : da Tunísia em 1881, do Marrocos em 1912, e a conquista de Trípoli pela Itália em 1911.

A terceira observação diz respeito ao povo agredido e colonizado como "um povo de ladrões", vivendo de "incursões, massacrando todos aqueles que resistissem" e praticando a escravidão sistematicamente. Em uma frase Engels relega ao pior "uma sociedade bem organizada, uma civilização peculiar, por vezes comparáveis àquelas da bacia mediterrânea" ${ }^{\text {. }}$. El retoma argumentos, dentre eles o de pirataria, que foram os pretextos para a expedição colonial e, em seguida, para a conquista com a mesma denominação.

Isto posto, e para além do desconhecimento, até mesmo da ignorância, de certos fatos históricos, é marcante ver Engels retomar por conta própria esteriótipos, ideias préconcebidas e preconceitos em moda sobre o Oriente. Em resumo, no caso específico que tratamos sobre a Argélia ${ }^{17}$, o jovem Engels e mesmo Marx, em menor medida, estão neste momento impregnados dos velhos e eternos preconceitos ${ }^{18}$ sobre o Oriente.

No texto de 1857, publicado em 1858 no tomo 1 do The New American Encyclopedie, Engels demonstra um domínio e um conhecimento mais acurado sobre a Argélia.

Ele não mantém mais a proposição de 1848 sobre esta guerra com tonalidades de extermínio, isto dezoito anos após o início da conquista e 10 anos depois de seu texto do Northern Star. "Desde a primeira ocupação da Argélia pelos franceses até hoje, este país mal fadado foi palco de incessantes banhos de sangue, de pilhagens e de violências. Cada cidade, grande ou pequena, foi conquistada casa por casa ... As tribos arábes e Kabyle, para os quais a independência é um bem precioso e o ódio da dominação estrangeira se sobrepõe as suas próprias vidas, foram submetidas e desestimuladas por terríveis pilhagens, ao longo das quais suas moradias e bens foram incendiados e pilhados, suas colheitas destruídas, e os infelizes habitantes deixados à guisa dos horrores da brutalidade e da sevícia. "19

Relacionado com este trecho, Engels observa esta "guerrra bárbara". No entanto, acrescenta curiosamente a religião cristã, ao passo que foi sob o signo desta última que os povos indígenas das Américas foram dizimados e que o rei Carlos X justificou a expedição colonial francesa em 1830.

No que diz respeito à civilização, Engels não teria anunciado rapidamente em 1848 que ela teria sido produzida pela colonização?

Neste texto ele afirma que a Argélia é habitada por "um povo de beduínos ladrões". No entanto, muda implicitamente esse julgamento de valor e demonstra inconscientemente que são os colonos franceses e seu exército que representam e correspondem ao perfil de "povo

\footnotetext{
16 Algérie, nation et société, Mostefa Lacheraf, éditions Maspéro, 1965.

17 Cf. Smaïl Hadj Ali, Os São Simonianos e a colonização da Argélia, Revista dos Estudos Avançados, nº 56 , janeiro/abril 2006 , USP, São Paulo, Brasil.

${ }_{18}$ Cf. A imagem europeia do árabe muçulmano, Smaïl Hadj Ali. Conferência proferida na Universidade de Bologne. Outubro de 1990. Texto inédito.

19 Marxisme et Algérie, p. 99
}

Argum., Vitória, v. 10, n. 2, p. 29-35, maio/ago. 2018. 
de ladrões" e de predadores. Os mesmos adjetivos que tinha utilizado em relação aos "beduínos" em 1848.

Infelizmente Marx, dado seu estado de saúde, não pôde se deslocar para ver a colonização em ação. Isto é comprovado nas cartas enviadas aos amigos da Argélia em 1882, onde passa por um tratamento para curar problemas pulmonares.

No entanto, como observa Galissot, algumas de suas proposições sobre a população colonizada deixam transparecer uma "espécie de folclore colonial" e de "tolerância" em relação à população dominada e submissa.

\section{CONCLUSÃO}

As propostas desenvolvidas por Marx e Engels nos textos consagrados a Argélia (1848 e 1857) não estariam intimamente relacionadas ao contexto político e histórico no seio dos movimentos revolucionários europeus? Movimentos em que "surge uma concepção bastante linear do progresso histórico, retomando a expressão civilização e uma perspectiva militante que reduz toda a luta aos antagonismos fundamentais : feudalismo, burguesia, proletariado"2o. Eles não estariam excluindo o que nos interessa, uma reflexão sobre a natureza das colonizações capitalistas nos países da periferia?

Ao refletir em termos de aceleração do processo histórico, necessariamente em direção do progresso, Marx e Engels não teriam super-avaliado e antecipado teoricamente os efeitos, considerados intrinsicamente positivos, da introdução das relações de produção capitalistas nos países da periferia ? Não teriam superestimado o impacto, supostamente benéfico, das relações de produção no contexto da colonização, que no caso da Argélia foi mais de povoamento?

Outra questão: como explicar a ausência de qualquer referência à questão da libertação nacional da Argélia ? Este ponto não estaria na ordem do dia?

Contudo, esta questão foi colocada em 1856 por Engels no caso da Irlanda : "Não nos damos conta que a pretensa liberdade dos cidadãos ingleses tem como fundamento a opressão das colônias" ${ }^{21}$, embora em seu texto sobre a Argélia de 1857 não haja nada neste sentido ${ }^{22}$.

Marx também considera e defende para a Irlanda a libertação nacional. É isso que ele explica ao seu amigo Kugelman em 1869: “... a classe operária inglesa nunca poderá realizar nada decisivo na Inglaterra, enquanto não rompa de forma clara com a política em relação à Irlanda, com a política das classes dominantes", e ele ainda acrescenta "não tomará a iniciativa da dissolução forçada de 1801"23.

Um mês mais tarde, em dezembro de 1869, ele reintera esta posição ao escrever a Engels : “... o rompimento das relações atuais com a Irlanda é de absoluto interesse para a classe

\footnotetext{
20 Ibidem, p. 20.

${ }^{21}$ Citado por René Galissot, p. 393.

${ }^{22}$ Necessariamente pensamos no Discurso contra a escravidão de Robespierre: "As colônias se deterioram se o custo é o da própria felicidade, glória e felicidade”. Conforme declarou Robespierre, p. 23.

23 Marxisme et Algérie, p. 393.
}

Argum., Vitória, v. 10, n. 2, p. 29-35, maio/ago. 2018. 
operária inglesa. Estou profudamente convicto disso .. Sempre acreditei que o desenvolvimento do movimento operário inglês permitirá derrubar o regime irlandês ... Um estudo mais sério me convenceu do contrário. A classe operária inglesa não fará nada antes de se livrar da Irlanda" ${ }^{24}$.

A recusa de Marx, de subordinar a emancipação do povo irlandês ao desenvolvimento operário inglês, não será adotada pelo partido comunista francês no caso da Argélia. Assim, privilegia-se a análise de classe e nega-se, ao menos minimiza-se segundo a situação, a dimensão nacional da luta pela independência do povo argelino. Esta posição repercutirá negativamente sobre o desenvolvimento revolucionário operário da Argélia, consequentemente, também sobre a tomada do caráter nacional por este movimento.

\section{Referências}

ALI, Smaïl Hadj. Os São Simonianos e a colonização da Argélia. Revista dos Estudos Avançados, Sao Paulo, n. 56, p. 225-236, jan./abr.20o6.

AMIN, Samir. O Manifesto comunista, 170 anos mais tarde. Argumentum, Vitória, v. 10, n. 2, p. 17-28, maio/ago. 2018.

GALISSOT, René (Org.). Marxisme et Algérie. Paris: Union Général D’Édition, 1976.

LACHERAF, Mostefa. Algérie, nation et société. Paris: Editions Maspéro, 1965.

MARX, K.; ENGELS, F. L’idéologie allemande. Paris: Éditions Sociales, 1965.

MARX, K.; ENGELS, F. Manifeste du Parti Communiste. Paris: Editions Sociales, 1959.

\section{Smail Hadj ALI}

Doutor em Ciências Sociais da Université de Haute Bretagne, Université d'Alger. Autor das seguintes obras no Brasil: Histórica e distanciamento crítico. Apresentado no Colloque Internacional : Poètiques de la modernité. UNESP, São José do Rio Preto. Reflexões sobre a modernidade. São Paulo: Paco Editorial, 2015. Notas sobre formas de dominação da esfera pública cultural contemporânea. Anais do Colloque : Margens da democracia: a literatura e a questão da diferença. Campinas: Edusp, 2015.

24 Idem, p. 393. 